\title{
Effects of Half-Time Cooling Using a Fan with Skin Wetting on Thermal Response During Intermittent Cycling Exercise in the Heat
} OPEN
ACCESS

\section{(c) $(1) \ominus$}

\author{
Authors

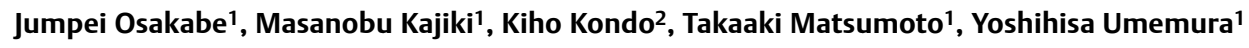

\author{
Affiliations \\ 1 Laboratory for Exercise Physiology and Biomechanics, \\ Graduate School of Health and Sport Sciences, Chukyo \\ University, Toyota, Japan \\ 2 Department of Nutrition, Faculty of Wellness, Shigakkan \\ University, Obu, Japan
}

\section{Key words}

evaporative heat loss, core temperature, thermal sensation, thermal stress

$\begin{array}{ll}\text { received } & 22.12 .2020 \\ \text { revised } & 07.08 .2021 \\ \text { accepted } & 10.08 .2021\end{array}$

\section{Bibliography}

Sports Medicine International Open 2021; 5: E91-E98

DOI 10.1055/a-1588-3126

ISSN 2367-1890

2021. The Author(s).

This is an open access article published by Thieme under the terms of the Creative Commons Attribution-NonDerivative-NonCommercial-License, permitting copying and reproduction so long as the original work is given appropriate credit. Contents may not be used for commercial purposes, or adapted, remixed, transformed or built upon. (https://creativecommons. org/licenses/by-nc-nd/4.0/).

Georg Thieme Verlag, Rüdigerstraße 14,

70469 Stuttgart, Germany

\section{Correspondence}

Jumpei Osakabe

Chukyo University, Graduate School of Health and Sport

Sciences, 101 Tokodachi, Kaizu-cho, Toyota Aichi

4700393

Japan

Tel.: + 08109058547403

osakabejunpei1229@gmail.com

\begin{abstract}
The present study investigated the effects of half-time (HT) break cooling using a fan and damp sponge on physiological and perceptual responses during the $2^{\text {nd }}$ half of a repeatedsprint exercise in a hot environment. Eight physically active men performed a familiarization trial and two experimental trials of a $2 \times 30$-min intermittent cycling exercise protocol with a 15 -min $\mathrm{HT}$ break in hot conditions $\left(35^{\circ} \mathrm{C}, 50 \%\right.$ relative humidity). Two experimental trials were conducted in random order: skin wetting with a fan $\left(\mathrm{FAN}_{\text {wet }}\right)$ and no cooling (CON). During the $2^{\text {nd }}$ half, a repeated-sprint cycling exercise was performed: i. e., $5 \mathrm{~s}$ of maximal pedaling (body weight $\times 0.075 \mathrm{kp}$ ) every minute, separated by $25 \mathrm{~s}$ of unloaded pedaling ( $80 \mathrm{rpm})$ and 30 s of rest. Rectal temperature, skin temperature (chest, forearm, thigh, and calf), heart rate, physiological strain index, rating of perceived exertion, thermal sensation, and comfort were significantly improved in the $\mathrm{FAN}_{\text {wet }}$ condition $(\mathrm{P}<0.05)$. There was no significant difference in the repeated-sprint cycling exercise performance between conditions. The results suggest that skin wetting with a fan during the HT break is a practical and effective cooling strategy for mitigating physiological and perceptual strain during the $2^{\text {nd }}$ half in hot conditions.
\end{abstract}

\section{Introduction}

Intermittent team sports such as field hockey, lacrosse, and soccer are played for between $60 \mathrm{~min}$ (in the cases of field hockey and lacrosse) and $90 \mathrm{~min}$ (in the case of soccer), sometimes requiring players to perform in hot and humid environmental conditions during summer (e. g., the summer Olympics and the International Fe- deration of Association Football World Cup). Intermittent exercise in hot conditions can rapidly increase core temperature [1]. Excessively elevated core and skin temperatures in hot conditions can increase the physiological and perceptual loads on athletes, negatively affecting endurance [2] and intermittent exercise performance [3] and increasing the risk of heat-related illness [4, 5]. Ath- 
letes in team sports (involving, for example, high school athletes) such as field hockey, lacrosse, and soccer are at risk of heat-related illness during competition and practice in the summer season [6]. Various practical methods of cooling the body have been studied and implemented in sports events to avoid the negative effects of thermal stress on health and exercise performance [7-9].

In general, team sports involve limited opportunities for body cooling. One opportunity for athletes to cool themselves is the halftime (HT) break. As such, ice/cooling vests are sometimes used as a cooling strategy during an HT break to reduce thermal strain. Chaen et al. (2019) reported that wearing a cooling vest during a (14-min) HT break reduced neck skin temperature, mean skin temperature (of the chest, arm, and thigh), and subjective responses (i. e., thermal sensation and perceived exertion) and subsequently improved repeated cycling sprint performance in the $2^{\text {nd }}$ half of the match [10]. Additionally, Brade et al. (2014) reported that wearing a cooling jacket during a (10 min) HT break reduced skin temperature and improved the subsequent repeated cycling sprint performance compared with the ingestion of an ice slushy [11]. When using the ice vest for body cooling, conduction is the main avenue of heat loss. Therefore, the body cooling effects of the application of an ice vest are determined by the total skin surface area that is directly in contact with the ice or gel packs. For that reason, because the net skin surface that is cooled by an ice vest might be smaller than the surface of the ice vest, no reduction in core temperature has been observed in previous studies $[10,11]$. Thus, wearing an ice vest during short rest breaks may be less effective in reducing the core temperature. The cost is also a consideration for using ice/cooling vests in many team sports. The team needs to prepare many ice vests because a team comprises a large number of athletes. In addition, the team needs to prepare a large freezer and freeze the gel and/or ice packs the day before the sports events. Additionally, several cooler boxes need to be prepared on the side of the field to avoid the melting of the gel and/or ice in sport events held in hot conditions.

The use of fan cooling in combination with skin wetting may be another method of HT break body cooling suitable for the HT break in team sports. The evaporation of water from the skin surface liberates a greater amount of heat $\left(2427 \mathrm{~J} \cdot \mathrm{g}^{-1}\right)$ [12] than melting ice $\left(334 \mathrm{~J} \cdot \mathrm{g}^{-1}\right)$. Only a sponge and bucket are needed to promote evaporative heat loss, and the evaporation of water can thus be used in a cost-effective method that is easy to set up during athletic competition. Therefore, a body cooling method for promoting evaporative heat loss using a fan and damp sponge may substitute for the use of ice/cooling vests in team sports. In particular, athletes who wear protective equipment under their uniform (e. g., lacrosse and American football athletes) cannot wear ice/cooling vests during short rest breaks, such as quarter and $\mathrm{HT}$ breaks. Meanwhile, although the skin surface area that contributes to evaporative heat loss is limited, the use of a fan and damp sponge may be a practical strategy of body cooling. It has been reported that fan cooling in combination with skin wetting during simulated tennis exercise in hot conditions mitigates the rise in core and skin temperatures and increases the time that the athletes can exercise compared with the ingestion of cold water $[13,14]$. However, in these previous studies, cooling was implemented in every break period (i. e., 16 rest periods of $90 \mathrm{~s}$ each and three 120 -s rest periods). Therefore, the effects of a fan combined with skin wetting cooling during an HT break on subsequent thermal and perceptual responses and exercise performance are currently unknown. To avoid heat-related illness and reduced exercise performance, information on the effectiveness of various cooling interventions is important to staff, coaches, trainers, and athletes in team sports.

In the present study, therefore, we investigated the effects of body cooling during an HT break using a fan and damp sponge on thermal and perceptual responses and the repeated-sprint exercise performance during the $2^{\text {nd }}$ half of a match of a simulated intermittent team sport under hot conditions. We hypothesized that body cooling using a fan and damp sponge during the HT break attenuates the elevation of the core and skin temperatures and improves thermal perception in the $2^{\text {nd }}$ half of intermittent exercise, which in turn improves repeated-sprint performance.

\section{Methods}

\section{Participants}

Eight non-heat-acclimatized, physically active men (mean \pm standard deviation [SD]; age $=23 \pm 1$ years, height $=170.9 \pm 3.8 \mathrm{~cm}$, body mass $[\mathrm{BM}] 65.5 \pm 3.5 \mathrm{~kg}, \dot{\mathrm{V}}_{2 \max }=51.8 \pm 5.0 \mathrm{ml} \cdot \mathrm{kg}^{-1} \cdot \mathrm{min}^{-1}$ ) participated in the present study. Participants performed more than two periods of endurance and/or intermittent exercise per week ( $\geq 30 \mathrm{~min} /$ per session). The participants were experienced in individual (cycling and athletics) or intermittent team sports (soccer, lacrosse and ultimate), and they were also experienced in sprint training using a cycle ergometer. Participants were asked to maintain their normal lifestyle activities, including their physical activity and nutritional habits, throughout the study period. All participants were healthy nonsmokers with no history of heat-related illness or cardiovascular disease. Participants were informed of the purpose of the study, as well as the requirements and risks involved, before providing written informed consent. Participants were instructed to refrain from strenuous physical activity, alcohol, caffeine, and drugs for 24 hours before all sessions. Participants selfdeclared their compliance with this instruction before each experimental session, and none of our participants breached this instruction. The study was approved (2020-16) by the Human Research Ethics Committee of Chukyo University, and conducted in accordance with the Declaration of Helsinki. The present study meets the ethical standards of this journal [15].

\section{Experimental design}

This study used a randomized crossover design. Participants completed one familiarization session before completing two experimental sessions. The experimental session consisted of two 30-min intermittent exercise periods separated by a 15 -min simulated HT break ( $>$ Fig. 1). The two different HT cooling interventions were implemented during the HT break. In one experimental session, participants were cooled by a fan with skin wetting $\left(\mathrm{FAN}_{\text {wet }}\right)$ at $\mathrm{HT}$, and for the other session, they were seated at rest on a chair (CON) during the HT break. To simulate hot and humid conditions, all experimental sessions were performed in a climate chamber (TBR12A4PX; ESPEC, Osaka, Japan) set at $35^{\circ} \mathrm{C}$ and $50 \%$ relative humidity $(\mathrm{RH})$. Environmental conditions in this study were referenced in previous studies $[16,17]$ that simulated team sports 


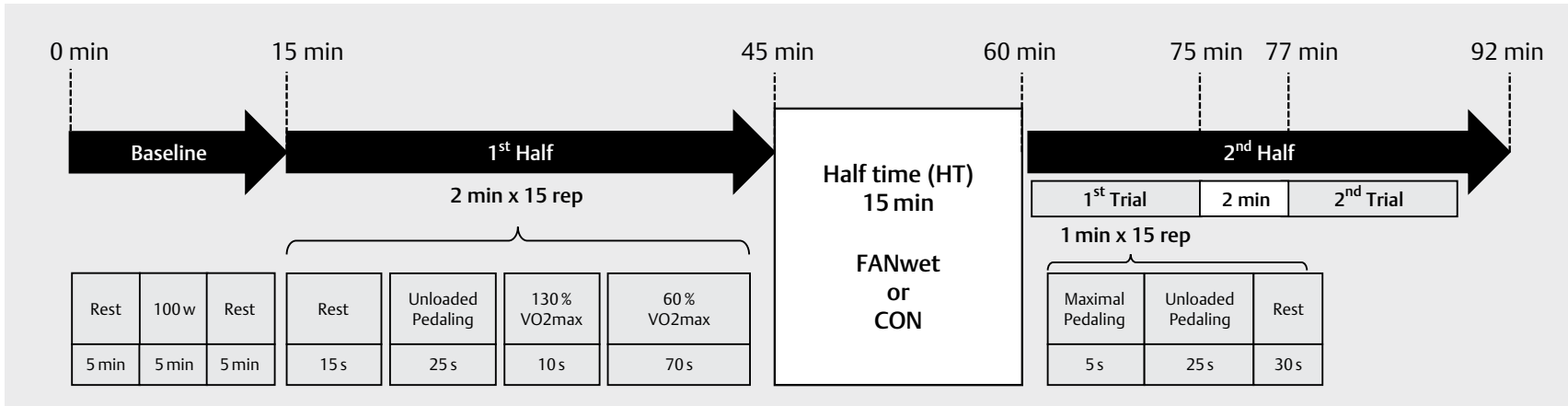

- Fig. 1 Exercise protocol.

match exercise in the heat using the climate chamber. During all experimental sessions (excluding the warm-up and $\mathrm{HT}$ ), participants were provided with airflow (at a flow rate of $0.8 \mathrm{~m} \cdot \mathrm{s}^{-1}$ ) from $1.5 \mathrm{~m}$ in front. For each participant, the two experimental sessions were implemented at the same time of day to control for circadian variations in body temperature and separated by at least 4 days. The participants' health and fatigue conditions were checked before each experimental session through verbal interview. To help promote hydration prior to the start of each session, participants were instructed to drink $500 \mathrm{~mL}$ of plain water 2 hours before all sessions.

\section{Procedure}

Prior to the experimental sessions, participants performed a progressive exercise test on a cycle ergometer (Fujin-Raijin; O.C. Labo, Tokyo, Japan) in a climate chamber set at a normal room temperature $\left(25^{\circ} \mathrm{C}\right.$ and $\left.50 \% \mathrm{RH}\right)$ to determine the maximal oxygen consumption $\left(\dot{\mathrm{V}}_{2 \mathrm{max}}\right)$. Prior to the test, the height and body mass of each participant were measured (MC-180; Tanita CO., Tokyo, Japan) to the nearest $0.1 \mathrm{~cm}$ and $50 \mathrm{~g}$, respectively. The progressive exercise test started at $100 \mathrm{~W}$ and increased by $25 \mathrm{~W}$ every 2 min until volitional fatigue. During the test, participants were required to maintain a pedal cadence of $80 \mathrm{rpm}$. The test was considered to be valid if two of the following three criteria were met: (1) there was a plateau in oxygen consumption, (2) the heart rate (HR) remained within $10 \%$ of the predicted maximum (220-age), and (3) the respiratory exchange ratio was greater than 1.05 [18]. During the test, a pre-calibrated automatic gas analyzer was used to measure the average oxygen consumption and carbon dioxide production at 30-s intervals (AE-310s; Minato Medical Science, Tokyo, Japan). The HR was continuously monitored during the test using an HR monitor (POLAR A300; Polar, Kempele, Finland).

Upon arrival at the laboratory, participants had urine samples collected and their nude body mass measured. After the placement of rectal and skin thermistors and an HR monitor, the participants entered a climate chamber. The participants rested on a cycle ergometer (Fujin-Raijin; O.C. Labo, Tokyo, Japan) for 5 min, then performed a standardized warm-up ( $100 \mathrm{~W}$ with a cadence of $80 \mathrm{rpm}$ ) for $5 \mathrm{~min}$, and then rested again for $5 \mathrm{~min}$. Participants then performed the first 30 -min period of intermittent exercise ( $1^{\text {st }}$ half). The 30-min intermittent exercise consisted of 15 reps of a 2-min exercise period. Each 2 -min period started with $15 \mathrm{~s}$ of passive rest followed by $25 \mathrm{~s}$ of unloaded cycling with a cadence of $80 \mathrm{rpm}$ and $10 \mathrm{~s}$ of high-intensity cycling (i. e., $130 \%$ of $\dot{\mathrm{V}}_{2 \max }, 80 \mathrm{rpm}$ ) and ended with 70 s of moderate-intensity cycling (i. e., $60 \%$ of $\dot{\mathrm{V}} \mathrm{O}_{2 \max }$, $80 \mathrm{rpm}$ ) [19]. To simulate the physical activity of a team sports match, the 30 -min intermittent exercise was based on a previous study designed to reflect a soccer match [19] but adjusted on the basis of our pilot experimental sessions. After the $1^{\text {st }}$ half, participants were required to get off the cycle ergometer and then change their clothes and sit on a chair. During the 15 min of HT, participants rested on the chair (CON) or underwent the cooling intervention $\left(\mathrm{FAN}_{\text {wet }}\right.$ ) in a climate chamber. Under both conditions, $2 \mathrm{~min}$ (from 45 to 46 min and from 59 to $60 \mathrm{~min}$ ) of the 15 -min HT break involved the participant moving to a chair or cycle ergometer. After HT, participants performed 30 min of a laboratory-based repeatedsprint exercise, broken up by 2 -min rest periods (i. e., 15 reps of 1 -min periods of the repeated-sprint cycling exercise for the $1^{\text {st }}$ and $2^{\text {nd }}$ trials) on a cycle ergometer ( $2^{\text {nd }}$ half). Each period started with $5 \mathrm{~s}$ of maximal pedaling at the load of weight $\times 0.075(\mathrm{kp})$ followed by $25 \mathrm{~s}$ of pedaling with no workload at a cadence of $80 \mathrm{rpm}$ and ended with $30 \mathrm{~s}$ of passive rest $[10,20]$. To maintain the participants' motivation, verbal encouragement was provided during the $2^{\text {nd }}$ half. After exercise, the nude body mass was measured, the rectal and skin thermistors and HR monitor were removed, and urine samples were collected. During the experimental session, participants consumed plain water $\left(10^{\circ} \mathrm{C}\right)$ before the $1^{\text {st }}$ half $(200 \mathrm{~mL})$, at $\mathrm{HT}(300 \mathrm{~mL})$, and in the 2 -min rest during the $2^{\text {nd }}$ half $(200 \mathrm{~mL})$.

\section{Cooling intervention}

In the $\mathrm{FAN}_{\text {wet }}$ session, participants were required to get off the cycle ergometer after the $1^{\text {st }}$ half, then sit on a chair (from 46 to $59 \mathrm{~min}$ ). Next, participants soaked a soft sponge $(10 \mathrm{~cm} \times 15 \mathrm{~cm}, 100 \%$ polyurethane) in a bucket of water at $\sim 20^{\circ} \mathrm{C}$ and then wrung out the wet sponge with both hands for $2 \mathrm{~s}$ over the bucket. Participants then applied the sponge to the skin of their face, neck, arms and thighs [13]. It was observed that water dripped off the body slightly. A 45-cm diameter fan (SF-45VS-1VPP, Suiden, Osaka, Japan) generating a wind speed of $6 \mathrm{~m} \cdot \mathrm{s}^{-1}$ was placed $1.5 \mathrm{~m}$ in front of the participants. The skin surface (of the face, neck, arms, and thighs) was moistened using the damp sponge in 1-min intervals, and the total cooling duration was 10 min of the 15-min HT break (from 48 to $58 \mathrm{~min}$, Fig. 1). The total volume of water that was applied to the skin surface in the 10 applications was calculated as: 
Total volume of water applied to the skin surface $=$ (weight of the damp sponge after being wrung out - weight of the damp sponge after being applied to the skin) $\times 10$.

According to our test experimental trial, the volume of water transferred to the skin surface with the damp sponge in each application was $42 \pm 11 \mathrm{~g}$.

In the CON condition, participants were required to get off the cycle ergometer after the $1^{\text {st }}$ half, and they then sat on a chair and rested for $13 \mathrm{~min}$ (from 46 to $59 \mathrm{~min}$ ) of the 15-min HT break.

\section{Measurements}

The urine specific gravity (USG) was measured using a digital USG scale (PAL-09S; Atago, Tokyo, Japan) as an index of the hydration status. To avoid dehydration before the experiment, a cutoff USG value of 1.020 was used [21]. Before the experiment, none of our participants exceeded this USG cutoff value. The nude body mass was measured using a scale (MC-180; Tanita CO., Tokyo, Japan) to the nearest $50 \mathrm{~g}$ before and after the experiment. A rectal thermistor probe (LT-ST08-11; Gram Corporation, Saitama, Japan) was positioned approximately $15 \mathrm{~cm}$ beyond the anal sphincter to measure the rectal temperature $\left(\mathrm{T}_{\text {re }}\right)$. Skin thermistors (LT-ST08-12; Gram corporation, Saitama, Japan) were attached to the chest ( $\left.T_{\text {chest }}\right)$, forearm $\left(T_{\text {arm }}\right)$, thigh $\left(T_{\text {thigh }}\right)$, and calf $\left(T_{\text {calf }}\right)$ to measure the mean skin temperature $\left({ }_{m} T_{s k}\right)$. Throughout the experimental sessions, rectal and skin temperature data were intermittently recorded using a data logger (LT-8; Gram Corporation, Saitama, Japan) at 30-s intervals. $\mathrm{m}_{\mathrm{sk}}$ was calculated using the formula of Ramanathan (1964) [22]:

$\mathrm{m}_{\text {sk }}=0.3 \times\left(\mathrm{T}_{\text {chest }}+\mathrm{T}_{\text {arm }}\right)+0.2 \times\left(\mathrm{T}_{\text {thigh }}+\mathrm{T}_{\text {calf }}\right)$.

The HR was measured using an HR monitor (POLAR A300; Polar, Kempele, Finland) every $30 \mathrm{~s}$ throughout the experimental session. The physiological strain index (PSI) was calculated as [23]:

$P S I=5 \times\left(T_{r e} t-T_{r e} 0\right) /\left(39.5-T_{r e} 0\right)+5 \times(H R t-H R 0) /(180-H R 0)$,

where $T_{r e} t$ and $H R t$ are values measured at a certain time point, $T_{r e} 0$ and $H R O$ are values measured at the beginning of exercise, and 39.5 and 180 are the mean maximum values of the core temperature and $H R$, respectively [23]. The data of $\mathrm{T}_{\mathrm{re}}, \mathrm{m} \mathrm{T}_{\mathrm{sk}}$ and PSI were calculated as 5-min averages (except for 0-15 min and 75-77 min, - Figure 1). The total sweat loss (TSL) was calculated as:

(BM before the experiment-BM after the experiment) + the amount of ingested liquid.

The rating of perceived exertion (RPE; 15-point scale) was recorded using the Borg scale [24]. Thermal sensation (TS) was measured using a nine-point scale ( 0 : very cold, 1 : cold, 2 : cool, 3 : slightly cool, 4: neutral, 5: slightly warm, 6: warm, 7: hot, and 8: very hot). Thermal comfort (TC) was measured using a seven-point scale ( -3 : very uncomfortable, -2 : uncomfortable, -1 : slightly uncomfortable, 0 : neutral, 1 : slightly comfortable, 2: comfortable, and 3: very comfortable) [25]. These perceptual indices were measured at pre- $1^{\text {st }}$ half (14 min), post- $1^{\text {st }}$ half $(45 \mathrm{~min})$, and post-HT (60 min) times. In addition, during the $2^{\text {nd }}$ half, the perceptual index was measured every five reps during the $1^{\text {st }}$ trial $(65,70,75 \mathrm{~min})$ and $2^{\text {nd }}$ trial $(82,87,92 \mathrm{~min})$. As an index of the repeated sprint-performance, mean power output was recorded every $5 \mathrm{~s}$ of repeated sprints for two sets of 15 repetitions.

\section{Statistical analyses}

All variables measured during the experiment are presented as mean \pm SD. The sample size was determined using $G^{*}$ power (version 3.1.9.7; Düsseldorf, Germany) and data from a previous study that investigated the effects of $\mathrm{FAN}_{\text {wet }}$ cooling during intermittent exercise in the heat [13]. To detect differences in $T_{r e}$ with a power of 0.8 and an $\alpha$-level of 0.05 , a minimum sample size of eight participants was required. All statistical analyses were performed using statistical software (SPSS version 26.0; IBM Corp., Armonk, NY, USA). The mean power output, $T_{r e}, m T_{s k}, H R, P S I, T S, T C, R P E, ~ U S G$, and BM were analyzed adopting a two-way (conditions $\times$ time) repeatedmeasures analysis of variance. When a significant interaction was observed, post hoc analyses were performed using the Bonferroni correction. The TSL was compared using a paired-sample $t$-test. Data normality was checked in a Shapiro-Wilk test, and where there was a significant violation of sphericity, Fvalues were adjusted using the Greenhouse-Geisser or Huynh-Feldt correction as appropriate. Statistical significance was set at $P<0.05$. According to Cohen's $d$ [26], the effect size (ES) was calculated as small (0.2-0.5), moderate $(0.5-$ 0.8 ) or large (>0.8). In this study, the value recorded before exercise $(0-15 \mathrm{~min})$ was defined as the baseline value.

\section{Results}

A significant interaction between condition and time $(P<0.05)$ was detected for $T_{\text {re }}$ and ${ }_{m} T_{s k}$. Changes in $T_{r e}$ and ${ }_{m} T_{s k}$ during the experiment are shown in $\mathbf{F i g}$. $\mathbf{2} \mathbf{a}$ and $\mathbf{2} \mathbf{b}$, respectively. $T_{\text {re }}$ at baseline was similar $(P>0.05)$ between conditions. However, $T_{\text {re }}$ was significantly lower $(P=0.04$, $E S=0.52-0.53$ : moderate $)$ in the $F A N_{\text {wet }}$ condition than in the CON condition at 87-92 min during the experiment ( $\triangleright$ Fig. 2a). None of the participants reached $\mathrm{T}_{\text {re }}$ at $39.5^{\circ} \mathrm{C}$ in this study. $m T_{s k}$ at the baseline was similar $(P>0.05)$ between conditions. However, $m T_{s k}$ was significantly lower $(P=0.01$, $E S=1.17-$ 3.2: large) in the $\mathrm{FAN}_{\text {wet }}$ condition than the $\mathrm{CON}$ condition from $\mathrm{HT}$ (50 $\mathrm{min}$ ) to the end of the experiment (92 min, > Fig. $\mathbf{2 b}$ ). $\mathrm{m}_{\mathrm{sk}}$ reached $31.1 \pm 1.7^{\circ} \mathrm{C}$ in the $\mathrm{FAN}_{\text {wet }}$ condition and $35.2 \pm 0.6^{\circ} \mathrm{C}$ in the $C O N$ condition at $60 \mathrm{~min}(\mathrm{P}=0.01, \mathrm{ES}=3.2$ : large), and $34.3 \pm 0.9^{\circ} \mathrm{C}$ in the $\mathrm{FAN}_{\text {wet }}$ condition and $35.5 \pm 1.0^{\circ} \mathrm{C}$ in the $\mathrm{CON}$ condition at $92 \mathrm{~min}(\mathrm{P}=0.01, \mathrm{ES}=1.2$ : large).

A significant interaction between condition and time $(P<0.05)$ was detected for the HR and PSI. Changes in the HR during the experiment are shown in $>$ Fig. 3. The HR was significantly lower $(P=0.01-0.02$, $E S=0.50-0.83$ : moderate-large $)$ in the $F_{A N} N_{\text {wet }}$ Condition than in the CON condition at 50 min and 65-92 min (except at 75-82 min). The changes in the PSI during the experiment are shown in Fig. 4. The PSI was significantly lower $(P=0.01-0.05$, $\mathrm{ES}=0.54-0.80$ : moderate) in the $\mathrm{FAN}_{\text {wet }}$ condition than in the CON condition at 70-92 $\mathrm{min}$ (except at 75-77 min).

The mean power output was not significantly different $(P>0.05)$ between conditions in each trial $\left(\mathrm{FAN}_{\text {wet }}: 1^{\text {st }} 673 \pm 63 \mathrm{~W}, 2^{\text {nd }}\right.$ $655 \pm 71$ W vs. CON: $1^{\text {st }} 688 \pm 75 W, 2^{\text {nd }} 667 \pm 87 W$ ). 


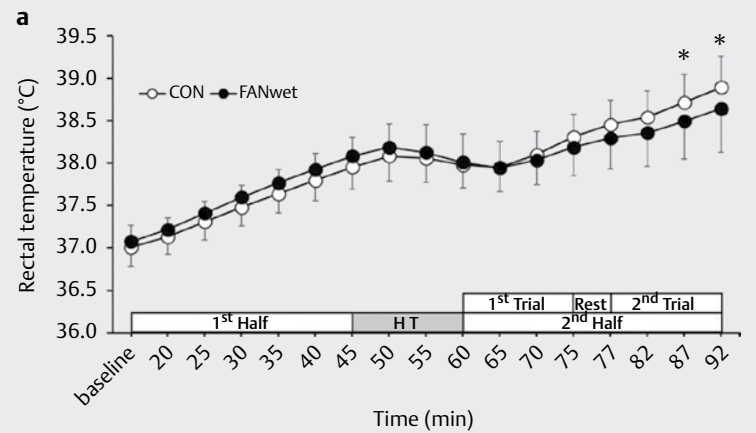

b

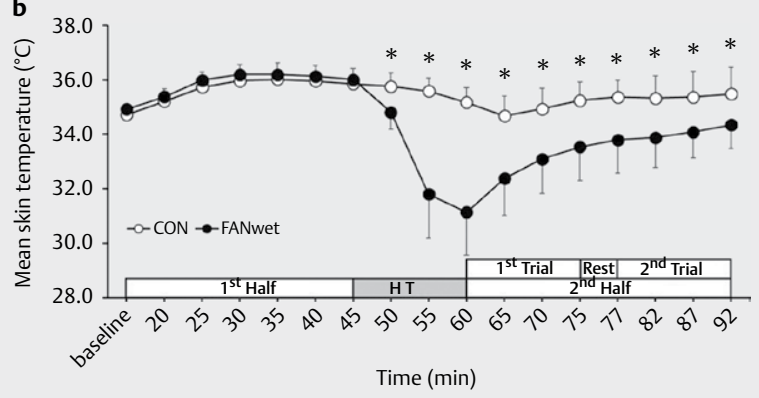

- Fig. 2 Changes in rectal temperature (a) and mean skin temperature (b) during the experimental session. Values are presented as means $\pm S D\left(n=8, F A N_{\text {wet }}: \bullet\right.$, and CON: 0$) .{ }^{*} P<0.05$ denotes a significant difference between $\mathrm{FAN}_{\text {wet }}$ and $\mathrm{CON}$ conditions.

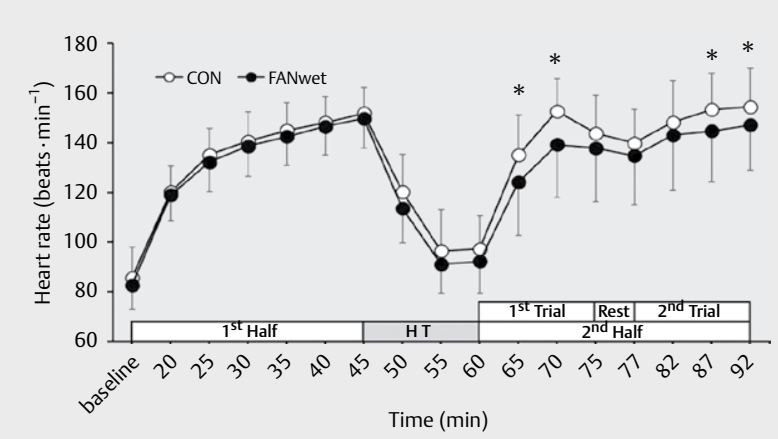

- Fig. 3 Changes in the heart rate during the experimental session. Values are presented as means $\pm S D\left(n=8, F_{\text {fNet }}: \bullet\right.$, and $\left.C O N: 0\right)$. ${ }^{*} \mathrm{P}<0.05$ denotes a significant difference between $\mathrm{FAN}_{\text {wet }}$ and CON conditions.

A significant interaction between the condition and time $(\mathrm{P}<$ 0.05 ) was detected for the TS and TC ( $\triangleright$ Table 1$)$. A significant main effect $(P<0.05)$ of the condition was detected for RPE ( $>$ Table 1$)$. The TS was significantly lower $(P=0.01-0.04$, ES $=0.95-4.0$ : large $)$ in the $\mathrm{FAN}_{\text {wet }}$ condition than the $\mathrm{CON}$ condition from $\mathrm{HT}$ ( $57 \mathrm{~min}$ ) to the end of the $1^{\text {st }}$ trial $(75 \mathrm{~min})$. The TC was also significantly lower $(P=0.01-0.33, E S=-1.13--1.74$ : large $)$ in the $F A N_{\text {wet }}$ condition than the CON condition from HT (57 min) to the end of the $1^{\text {st }}$ trial (75 min). The RPE was significantly lower $(P=0.01)$ in the $F N_{\text {wet }}$ condition than the CON condition during the $2^{\text {nd }}$ half of the expe-

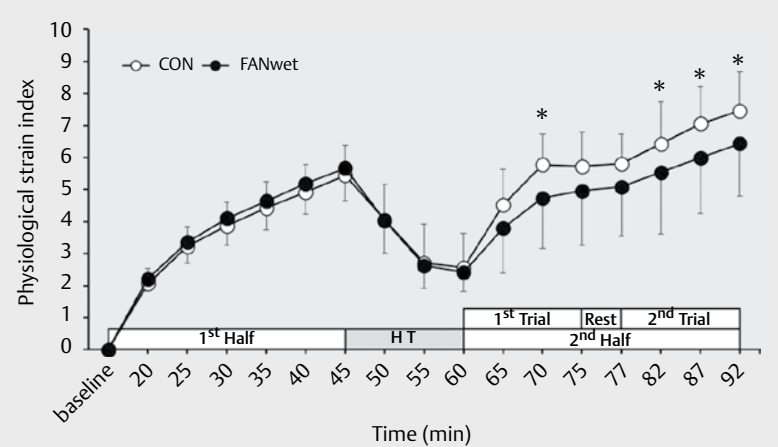

- Fig. 4 Changes in the physiological strain index during the experiment. Values are presented as means $\pm S D\left(n=8, F_{\text {Fet }}: \bullet\right.$, and $C O N$ : O). ${ }^{*} \mathrm{P}<0.05$ denotes a significant difference between $\mathrm{FAN}_{\text {wet }}$ and CON conditions.

riment. $>$ Table 2 shows the hydration states before and after the experiments. No significant differences $(P>0.05)$ were found for the BM, USG, or TSL between conditions.

\section{Discussion}

The present study examined the effects of cooling using a fan and damp sponge during the HT break on the subsequent repeatedsprint exercise performance and physiological and perceptual responses in a hot and humid environment $\left(35^{\circ} \mathrm{C}, 50 \% \mathrm{RH}\right)$. No significant improvement was found in the $\mathrm{FAN}_{\text {wet }}$ condition compared with the CON condition for the repeated-sprint exercise performance. However, the $\mathrm{FAN}_{\text {wet }} \mathrm{HT}$ break cooling intervention was more effective than the CON condition at mitigating thermal and perceptual strain in the $2^{\text {nd }}$ half. At the end of the $2^{\text {nd }}$ half, $T_{\text {re }}$ was $0.25^{\circ} \mathrm{C}$ lower in the $\mathrm{FAN}_{\text {wet }}$ condition than in the $\mathrm{CON}$ condition. Additionally, $\mathrm{m} \mathrm{T}_{\mathrm{sk}}$ was $1.1^{\circ} \mathrm{C}$ lower at the end of the $2^{\text {nd }}$ half in the $\mathrm{FAN}_{\text {wet }}$ condition. Moreover, $\mathrm{HR}$ and PSI during the $2^{\text {nd }}$ half were significantly lower in the $\mathrm{FAN}_{\text {wet }}$ condition. In addition, the RPE, TS, and TC improved during the $2^{\text {nd }}$ half in the $\mathrm{FAN}_{\text {wet }}$ condition. Thus, to mitigate thermal and perceptual strains in the $2^{\text {nd }}$ half in team sports, cooling using a fan and damp sponge during the HT break may be a practical and effective cooling strategy.

Our study revealed that 10 min of the $\mathrm{FAN}_{\text {wet }}$ cooling intervention during the HT break significantly attenuated the elevation of the rectal temperature during the $2^{\text {nd }}$ half ( $>$ Fig. 2a). The difference in $\mathrm{T}_{\text {re }}$ at the end of the $2^{\text {nd }}$ half was $0.25^{\circ} \mathrm{C}(P=0.04, E S=0.53)$. In previous studies $[13,14]$, body cooling using a fan and damp sponge in rest breaks (lasting 90 and 120 s) during intermittent running exercise (simulated tennis-match play) was reported to attenuate the increase in $\mathrm{T}_{\text {re }}$. In the current study, we observed a smaller increase in $\mathrm{T}_{\mathrm{re}}$ during subsequent exercise after the application

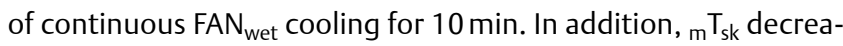
sed by $4.1^{\circ} \mathrm{C}\left(\mathrm{FAN}_{\text {wet }}: 31.1 \pm 1.7^{\circ} \mathrm{C}\right.$; $\left.\mathrm{CON}: 35.2 \pm 0.6^{\circ} \mathrm{C}\right)$ at HT (60 min) and $1.1^{\circ} \mathrm{C}\left(\mathrm{FAN}_{\text {wet }}: 34.4 \pm 0.9^{\circ} \mathrm{C}\right.$; $\left.\mathrm{CON}: 35.5 \pm 1.0^{\circ} \mathrm{C}\right)$ at the end of the $2^{\text {nd }}$ half ( $92 \mathrm{~min}$ ). Because $50 \%$ of $\mathrm{T}_{\text {sk }}$ was determined by sensors placed on the forearm and thigh, the reduction in $\mathrm{m}_{\mathrm{sk}}$ appeared to be due to the cooling of a large surface area of the body, 
- Table 1 Changes in thermal sensation, thermal comfort, and rating of perceived exertion during the experiment.

\begin{tabular}{|c|c|c|c|c|c|c|c|c|c|c|}
\hline & & & & & \multicolumn{3}{|c|}{$1^{\text {st }}$ trial } & \multicolumn{3}{|c|}{$2^{\text {nd }}$ trial } \\
\hline & & Pre $1^{\text {st }}$ half & Post 1st half & HT & 5 rep & 10 rep & 15 rep & 20 rep & 25 rep & 30 rep \\
\hline \multirow[t]{2}{*}{ TS } & CON & $5.5 \pm 0.9$ & $7.0 \pm 0.9$ & $6.3 \pm 0.7$ & $6.5 \pm 0.7$ & $7.0 \pm 0.5$ & $7.4 \pm 0.5$ & $7.4 \pm 0.5$ & $7.6 \pm 0.5$ & $7.6 \pm 0.5$ \\
\hline & FANwet & $5.9 \pm 0.9$ & $7.0 \pm 0.9$ & $2.6 \pm 1.0 *$ & $5.4 \pm 1.0^{*}$ & $6.0 \pm 1.0^{*}$ & $6.5 \pm 1.1^{*}$ & $6.8 \pm 1.2$ & $6.8 \pm 1.2$ & $6.9 \pm 1.3$ \\
\hline \multirow[t]{2}{*}{ TC } & CON & $-0.4 \pm 1.0$ & $-1.6 \pm 0.9$ & $-0.8 \pm 0.8$ & $-1.6 \pm 0.5$ & $-2.1 \pm 0.3$ & $-2.4 \pm 0.5$ & $-2.5 \pm 0.5$ & $-2.8 \pm 0.4$ & $-2.8 \pm 0.4$ \\
\hline & FANwet & $-0.1 \pm 0.8$ & $-1.9 \pm 0.6$ & $1.3 \pm 1.3^{*}$ & $-0.5 \pm 0.7^{*}$ & $-1.6 \pm 0.5^{*}$ & $-1.8 \pm 0.4^{*}$ & $-2.1 \pm 0.3$ & $-2.4 \pm 0.5$ & $-2.6 \pm 0.5$ \\
\hline \multirow[t]{2}{*}{ RPE } & CON & & & & $16.3 \pm 1.1$ & $17.5 \pm 1.1$ & $18.6 \pm 0.9$ & $18.9 \pm 0.3$ & $19.1 \pm 0.6$ & $19.6 \pm 0.5$ \\
\hline & FANwet $\dagger$ & & & & $15.3 \pm 1.3$ & $16.9 \pm 1.2$ & $18.1 \pm 1.1$ & $18.3 \pm 0.8$ & $18.5 \pm 0.7$ & $19.4 \pm 0.5$ \\
\hline
\end{tabular}

${ }^{*}$ shows significant difference between conditions, FAN $_{\text {wet }}$ Vs. CON $(\mathrm{P}<0.05)$. $\dagger$ shows a significant main effect between conditions, FAN $\mathrm{N}_{\text {wet }}$ Vs. CON $(P<0.05)$. TS: thermal sensation, TC: thermal comfort, RPE: rating of perceived exertion.

- Table 2 Hydration state pre-and post-experiment.

\begin{tabular}{|l|l|l|l|l|l|l|}
\hline \multirow{2}{*}{} & \multicolumn{2}{|c|}{ CON } & \multicolumn{2}{c|}{ FANwet } \\
\cline { 2 - 6 } & Pre & & Post & Pre & Post \\
\hline Body mass (kg) & $65.6 \pm 3.4$ & & $64.6 \pm 3.3$ & $65.5 \pm 3.5$ & $64.6 \pm 3.4$ \\
\hline Total sweat loss (kg) & & $1.7 \pm 0.2$ & & & $1.6 \pm 0.3$ & \\
\hline Urine specific gravity & $1.009 \pm 0.007$ & & $1.013 \pm 0.008$ & $1.011 \pm 0.009$ & $1.014 \pm 0.008$ \\
\hline
\end{tabular}

including the forearm and thigh, via skin wetting and airflow. Thus, although the cooling intervention was implemented for only 10 min, the results suggest that the $\mathrm{FAN}_{\text {wet }}$ cooling intervention promoted evaporative heat loss and attenuated the elevation of core and skin temperatures during subsequent exercise in hot conditions.

The present study revealed that the FAN ${ }_{\text {wet }}$ HT break cooling intervention significantly attenuated the increase in the HR during the $2^{\text {nd }}$ half. The difference in the HR between conditions was approximately $10 \mathrm{bpm}$ at the end of the $2^{\text {nd }}$ half $\left(\mathrm{FAN}_{\text {wet }}: 145 \pm 20\right.$ bpm; CON: $155 \pm 17 \mathrm{bpm}$ ). The reduction in the HR may have been affected by the reduction in skin temperature. In the current study, the difference in $\mathrm{m}_{\mathrm{sk}}$ after the 10 min of $\mathrm{FAN}_{\text {wet }}$ intervention was $4.1^{\circ} \mathrm{C}$ (60 min). A reduction in skin temperature leads to a reduction in peripheral skin blood, which results in a circulatory shift to central blood circulation [27] and may mitigate cardiovascular strain during exercise in the heat [28]. Some previous studies reported that a $\mathrm{FAN}_{\text {wet }}$ cooling intervention during exercise in the heat reduces the HR $[13,14]$. For example, Schranner et al. (2017) reported that a $\mathrm{FAN}_{\text {wet }}$ cooling intervention during rest periods (90-s rest periods between games and 120 -s rests between sets) of simulated tennis match play in a hot/humid environment significantly reduced mean skin temperature and HR compared with the ingestion of cold water $\left(\sim 7^{\circ} \mathrm{C}\right)$. The RPE was also significantly lower in the $\mathrm{FAN}_{\text {wet }}$ condition than the CON condition during exercise [13]. The measurement of the HR is related to the RPE, and a lower RPE was observed in this study. These data suggest that a $F A N_{\text {wet }}$ cooling intervention during rest periods of exercise in hot conditions positively affects cardiovascular and perceptual strain.

Schranner et al. (2017) and Lynch et al. (2018) reported that, compared with the ingestion of cold water, the mean exercise time (i. e., the time to exhaustion or reaching $\mathrm{T}_{\text {re }}$ at $39.5^{\circ} \mathrm{C}$ ) in hot conditions was longer when the body was cooled using a fan with skin wetting $[13,14]$. However, in this study, no significant difference was found in the repeated cycling sprint performance between conditions. These inconsistent findings may be due to differences in the study protocols. The previous studies examined endurance exercise to exhaustion, in contrast to the maximal sprint exercise considered in the current study. In our study, therefore, repeated bouts of explosive power for maximal pedaling may have induced central fatigue in both conditions, leading to the absence of a significant difference in repeated-sprint performance.

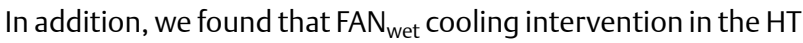
break significantly reduced the PSI during the $2^{\text {nd }}$ half. Because the $P S I$ is based on $T_{\text {re }}$ and the HR [23], a lower $T_{\text {re }}$ and HR during the $2^{\text {nd }}$ half in the $\mathrm{FAN}_{\text {wet }}$ condition may have contributed to the maintenance of the lower PSI compared with the CON condition. At the end of exercise (92 min), the PSI was significantly lower $(P=0.01$, $E S=0.71)$ in the $F_{\text {wet }}$ condition $(6.4 \pm 1.7)$ than in the CON condition (7.5 \pm 1.2 ). Because a PSI value of 7.5 or more is considered to indicate that an individual is at risk of heat-related illness [29], our data suggest that the $\mathrm{FAN}_{\text {wet }}$ cooling method may be effective for attenuating physiological strain, potentially lowering the risk of heat-related illness in hot and humid environments.

The TS and TC were also improved by the $\mathrm{FAN}_{\text {wet }}$ cooling intervention during the $2^{\text {nd }}$ half. In particular, greater improvements in the TS and TC were observed immediately after HT. Because increased skin temperature negatively affects the TS and TC [30,31], the improvement in the thermal response in the current study may have been due to the reduction in skin temperature $[10,13]$. A similar improvement in the subjective response due to $\mathrm{FAN}_{\text {wet }} \mathrm{CoO}-$ ling during exercise in the heat was reported in previous studies $[13,14]$. These results show that fan cooling in combination with skin wetting can induce a better subjective thermal response immediately after implementation, which is sustained through the latter stage of the $2^{\text {nd }}$ half.

Although an electricity supply is needed to use a fan, the present study found the FAN $_{\text {wet }}$ cooling intervention is a feasible HT 
cooling strategy for preventing heat-related illness in team sport competitions. The $\mathrm{FAN}_{\text {wet }}$ cooling intervention needs only a fan, sponge, and bucket and it may therefore be cost-effective and feasible for athletes belonging to teams at various levels of competitiveness compared with other cooling interventions, such as immersion in cold water and wearing a cooling vest. Lacrosse and American football athletes are required to wear protective equipment, which inhibits evaporative, convective, and radiant heat loss [4]. Meanwhile, the use of large mechanical fans increases airflow and assists the movement of the microclimate next to the skin and facilitates convective and evaporative heat loss. Therefore, although the skin surface that is exposed to the outside is limited, FAN $_{\text {wet }}$ cooling intervention may be a feasible HT cooling strategy for lacrosse and American football athletes because this cooling strategy can be implemented without taking off protective equipment. Further study is needed to investigate the effects of the $\mathrm{FAN}_{\text {wet }}$ cooling intervention on lacrosse and American football athletes. Coaches and staff should implement an appropriate HT cooling strategy, taking into account cost, equipment, and rules.

The present study has several limitations that should be considered. A 10 -min period of FAN $_{\text {wet }}$ cooling intervention was implemented in this study. However, in general, HT breaks have a length of 10-15 min in many team sports (e. g., lacrosse, soccer, and rugby). From the point of view of strategy meetings during $\mathrm{HT}$ in locker rooms or on the bench, a shorter cooling intervention time may be required in practice. In addition, although the HT cooling intervention was implemented in hot conditions in the current study, the effects of the $\mathrm{FAN}_{\text {wet }}$ cooling intervention in cooler conditions, such as the locker room, are unclear. Further research is needed to assess the effects of the duration and environmental conditions of the FAN $_{\text {wet }}$ cooling intervention during the HT break on thermal and subjective strain, and exercise performance. According to the activity profiles of team sports, an ability to perform repeated high-intensity running and the sprint exercise performance are important for success in intermittent team sports [32]. We thus evaluated the repeated cycling sprint performance in the current study. However, intermittent team sports typically involve running, and there are differences between cycling and running in terms of locomotion and metabolic responses. Further study is required to assess the effects of the $\mathrm{FAN}_{\text {wet }}$ cooling intervention on the running sprint exercise performance. In this study, verbal encouragement was provided in the $2^{\text {nd }}$ half only. However, it is of concern that the verbal encouragement approach that was implemented in this study could compromise its ability to examine the intervention effects. Finally, because the experiment in the present study was conducted in a climate chamber, we could not apply solar radiation or a sufficient air speed. Solar radiation and air speeds affect core and skin temperatures and exercise performance [33, 34]. Therefore, further research should be conducted in outdoor conditions to assess the usefulness of the intervention for real team sports competitions.

\section{Conclusion}

The present study demonstrated that 10 min of body cooling using a fan with skin wetting during a simulated $\mathrm{HT}$ break between two 30 -min bouts of intermittent exercise in hot conditions significant- ly attenuated increases in both rectal and skin temperatures in hot conditions, thereby reducing the HR, PSI, RPE, TS, and TC. Thus, fan cooling in combination with skin wetting may be a useful cooling strategy for team sports held in hot conditions.

\section{Acknowledgements}

The authors would like to acknowledge the participants for their contribution to the study. We thank Benjamin Knight, MSc., from Edanz Group (https://en-author-services.edanz.com/ac) for editing a draft of this manuscript.

\section{Conflicts of Interest}

The authors declare that they have no conflict of interest.

\section{References}

[1] Duffield R, Coutts AJ, Quinn J. Core temperature responses and match running performance during intermittent-sprint exercise competition in warm conditions. J Strength Cond Res 2009; 23: 1238-1244

[2] Nybo L, Rasmussen P, Sawka MN. Performance in the heat-physiological factors of importance for hyperthermia-induced fatigue. Compr Physiol 2014; 4: 657-689

[3] Ozgünen KT, Kurdak SS, Maughan RJ et al. Effect of hot environmental conditions on physical activity patterns and temperature response of football players. Scand J Med Sci Sports 2010; 20: 140-147

[4] Casa DJ, DeMartini JK, Bergeron MF et al. National Athletic Trainers' Association Position Statement: Exertional Heat Illnesses. J Athl Train 2015; 50: 986-1000

[5] Wendt D, van Loon L], Lichtenbelt WD. Thermoregulation during exercise in the heat: strategies for maintaining health and performance. Sports Med 2007; 37: 669-682

[6] Kerr ZY, Casa DJ, Marshall SW et al. Epidemiology of exertional heat illness among U.S. high school athletes. Am J Prev Med 2013; 44: 8-14

[7] Bongers CC, Hopman MT, Eijsvogels TM. Cooling interventions for athletes: an overview of effectiveness, physiological mechanisms, and practical considerations. Temperature (Austin) 2017; 4: 60-78

[8] Chalmers SM. In-play cooling strategies for sport in hot and humid conditions * . Temperature (Austin) 2017; 4: 353-355

[9] Racinais S, Alonso JM, Coutts AJ et al. Consensus recommendations on training and competing in the heat. Scand J Med Sci Sports 2015; 25 : 6-19

[10] Chaen Y, Onitsuka S, Hasegawa H. Wearing a cooling vest during half-time improves intermittent exercise in the heat. Front Physiol 2019; 10: 711

[11] Brade C, Dawson B, Wallman K. Effects of different precooling techniques on repeat sprint ability in team sport athletes. Eur J Sport Sci 2014; 14: 84-91

[12] Wenger CB. Heat of evaporation of sweat: thermodynamic considerations. J Appl Physiol 1972; 32: 456-459

[13] Schranner D, Scherer L, Lynch GP et al. In-play cooling interventions for simulated match-play tennis in hot/humid conditions. Med Sci Sports Exerc 2017; 49: 991-998

[14] Lynch GP, Périard JD, Pluim BM et al. Optimal cooling strategies for players in Australian Tennis Open conditions. J Sci Med Sport 2018; 21: 232-237 
[15] Harriss D, MacSween A, Atkinson G. Ethical standards in sport and exercise science research: 2020 update. Int J Sports Med 2019; 40: 813-817

[16] Chalmers S, Siegler J, Lovell R et al. Brief in-play cooling breaks reduce thermal strain during football in hot conditions. J Sci Med Sport 2019; 22: 912-917

[17] Maroni T, Dawson B, Dennis M et al. Effects of half-time cooling using a cooling glove and jacket on manual dexterity and repeated-sprint performance in heat. J Sports Sci Med 2018; 17: 485-491

[18] Stanley J, Leveritt M, Peake JM. Thermoregulatory responses to ice-slush beverage ingestion and exercise in the heat. Eur J Appl Physiol 2010; 110: 1163-1173

[19] Yanaoka T, Hamada Y, Kashiwabara K et al. Very-short-duration, low-intensity half-time re-warm up increases subsequent intermittent sprint performance. J Strength Cond Res 2018; 32: 3258-3266

[20] Naito T, Hamamura M, Muraishi K et al. Impact of ice slurry ingestion during break-times on repeated-sprint exercise in the heat. Sports Med Int Open 2020; 4: 45-52

[21] Sawka MN, Burke LM, Eichner ER et al. American College of Sports Medicine position stand. Exercise and fluid replacement. Med Sci Sports Exerc 2007; 39: 377-390

[22] Ramanathan NL. A new weighting system for mean surface temperature of the human body. J Appl Physiol 1964; 19: 531-533

[23] Moran DS, Shitzer A, Pandolf KB. A physiological strain index to evaluate heat stress. Am J Physiol 1998; 275: 129-134

[24] Borg GA. Psychophysical bases of perceived exertion. Med Sci Sports Exerc 1982; 14: 377-381

[25] Kajiki M, Yamashita N, Ito R et al. Effects of air-perfused rucksack on physiological and perceptual strain during low-intensity exercise in a hot environment. Temperature (Austin) 2020; 7: 157-164
[26] Cohen J. Statistical Power Analysis for the Behavioural Sciences. 2nd ed. Hillsdale (NJ): Lawrence Erbaum Associates; 1988; 567

[27] Hasegawa H, Takatori T, Komura T et al. Wearing a cooling jacket during exercise reduces thermal strain and improvesendurance exercise performance in a warm environment. J Strength Cond Res 2005; 19: 122-128

[28] Sleivert GG, Cotter JD, Roberts WS et al. The influence of whole-body vs. torso pre-cooling on physiological strain and performance of high-intensity exercise in the heat. Comp Biochem Physiol A Mol Integr Physiol 2001; 128: 657-666

[29] Buller M], Latzka WA, Yokota M et al. A real-time heat strain risk classifier using heart rate and skin temperature. Physiol Meas 2008; 29: 79-85

[30] Flouris AD, Schlader Z]. Human behavioral thermoregulation during exercise in the heat. Scand J Med Sci Sports 2015; 25: 52-64

[31] Yao Y, Lian Z, Liu W et al. Experimental study on physiological responses and thermal comfort under various ambient temperatures. Physiol Behav 2008; 93: 310-321

[32] Taylor J, Macpherson T, Spears I et al. The effects of repeated-sprint training on field-based fitness measures: a meta-analysis of controlled and non-controlled trials. Sports Med 2015; 45: 881-891

[33] Otani H, Kaya M, Tamaki A et al. Effects of solar radiation on endurance exercise capacity in a hot environment. Eur J Appl Physiol 2016; 116: 769-779

[34] Otani H, Kaya M, Tamaki A et al. Air velocity influences thermoregulation and endurance exercise capacity in the heat. Appl Physiol Nutr Metab 2018; 43: 131-138 